\title{
EL DERECHO \\ COMO INSTITUCIÓN ESPONTÁNEA
}

\author{
JUAN R. RALLO*
}

En este artículo trataremos de mostrar la viabilidad y conveniencia de un orden jurídico descentralizado frente a una organización monocéntrica que genere e imponga sus propios mandatos jurídicos.

En la primera parte, comenzaremos con al análisis hayekiano del orden espontáneo para explicar las distintas características y etapas que componen una institución. En la segunda, aplicaremos estas conclusiones al caso particular del derecho.

Con este análisis podremos elaborar ciertas predicciones y explicaciones sobre la evolución política del Estado y pergeñar estrategias para lograr defender la libertad.

I.

INSTITUCIONES: CARACTERÍSTICAS, FUNDAMENTOS, DESARROLLO Y CRISIS

\section{Características de las instituciones}

Para Hayek las instituciones sociales «no sólo no han sido creadas por ninguna mente, sino que su persistencia y funcionamiento dependen de las acciones de gentes que no están impulsadas por el deseo de preservarlo» ${ }^{1}$. Ello no significa, sin embargo, que las instituciones carezcan de utilidad ya que «las instituciones que se desarrollan

\footnotetext{
* Universidad de Valencia e Instituto Juan de Mariana.

${ }^{1}$ Friedrich August von Hayek, La Contrarrevolución de la Ciencia, Unión Editorial, 2003, pág. 135.
} 
espontáneamente son útiles porque fueron las condiciones sobre las que se basó el desarrollo humano posterior»².

Por tanto, las instituciones vendrían caracterizadas por tres rasgos: a) la ausencia de autor o mente creadora concreta, b) continua evolución descentralizada de las mismas a través del mecanismo de prueba y error, y c) la utilidad que le atribuyen sus participantes.

De estos tres rasgos podemos deducir la condición necesaria de Hayek para una sociedad libre: la ausencia de un fin universal que restrinja los fines particulares. De hecho, la grandeza de las instituciones reside en que aun no habiendo sido diseñadas por hombre alguno y no estar constreñidas por una finalidad inicial resultan tremendamente flexibles para que cada individuo las adapte a sus fines concretos sin, por ello, dañar las expectativas ajenas.

En otras palabras, las instituciones permiten un gran margen de certidumbre sobre el rumbo de nuestras propias acciones. Un solo individuo no puede utilizar la institución como medio de agresión hacia otro individuo, ni tampoco puede, a través de la propia institución, modificarla bruscamente. De esta manera, encontramos dos nuevos rasgos de las instituciones que no son más que la derivación lógica de los tres anteriores: d) la voluntariedad y e) la estabilidad.

Una «institución» coactiva no puede ser institución por cuanto consolida comportamientos pautados «inútiles» (violando así el tercer rasgo de la «utilidad»). En efecto, cuando el planificador impone su voluntad a los demás individuos provoca inevitablemente una mengua en su utilidad ${ }^{3}$. Pero, además, esta consolidación de los comportamientos «inútiles» ocasiona la

2 Ibidem, pág. 133.

3 Dado que sin voluntariedad no es posible la utilidad, podría parecer sugerente unificar las características c) y d). Es más, gracias al concepto rothbardiano de preferencia demostrada, sabemos que no se producirá la voluntaria participación sin la expectativa de utilidad. Con todo, puede ser útil por motivos pedagógicos contraponer las características a) y c), esto es, que a pesar de que ninguna mente ha creado la institución, resulta útil — se inserta en la cadena de medios— para conseguir los fines particulares de cada individuo. Además también nos permite analizar desde distintas perspectivas (utilidad sin voluntariedad) la legislación estatal. 
petrificación de la institución y la paralización de su característico proceso de prueba y error (b). La violencia permite consolidar instituciones que ya deberían haber desaparecido o haber adoptado una forma totalmente distinta. Y es que, toda institución es fruto de las consecuencias no intencionadas de las acciones de los individuos, de manera que al modificar su acción (por ejemplo, al dejar de participar en la institución), provocan también los cambios necesarios para que ésta mejore o se reoriente.

Por otro lado, aunque la influencia de la acción de cada individuo tiene repercusiones sobre la institución, ninguna influencia es suficientemente grande como para provocar un cambio abrupto ${ }^{4}$. De hecho, si alguien tuviera el poder para modificar por sí solo la institución (y no a través de la acción sucesiva del resto de las personas), nos encontraríamos ante el caso de una «mente consciente planificadora» y ello violaría nuestra característica a).

La violación de cualquiera de estos dos rasgos provocará que las instituciones dejen de cumplir su labor esencial en una sociedad libre, esto es, permitir la coordinación de los individuos sin imponerles un fin común.

De ahí que podamos adelantar otra característica de las instituciones: f) la autocorrección. Hemos dicho que las instituciones son fruto de las consecuencias no intencionadas de las acciones de los individuos. Si los individuos pueden fallar, ello significa que las acciones no intencionadas de los individuos, esto es, las instituciones, también podrán ser y generar errores.

\footnotetext{
${ }^{4}$ El caso de los líderes no supone una excepción a nuestra afirmación. Debemos distinguir nítidamente entre el hecho de que una persona fije unilateral y bruscamente las reglas por las que el resto de los individuos van a regirse a partir de un momento dado y que un individuo persuada a un numeroso grupo de individuos para que modifiquen y adapten su conducta de manera acelerada y ello provoque un cambio súbito de la institución. Mientras que en el primer caso, la modificación de la institución fuerza un cambio en las acciones de los individuos, en el segundo, el cambio de acción de los individuos fuerza una modificación de la institución (Pero es el propio conjunto de individuos quien precipita el cambio). O dicho de otra manera, si mañana el gobierno suspendiera el pago de deuda pública, provocaría el hundimiento del sistema monetario. En cambio, si el gobierno convence a los ciudadanos para que no reclamen la deuda pública, simplemente logrará una adaptación de las instituciones monetarias a las nuevas necesidades de la gente.
} 
Sin embargo, las instituciones podrán autocorregirse siempre que permitan al mismo proceso evolutivo generar los mecanismos necesarios para desechar aquellos comportamientos pautados inútiles. Como ya hemos explicado más arriba, cuando el individuo decide no valerse de una institución o modificar el uso que le da, la institución, a través de la adaptación del resto de usuarios, experimenta un cambio.

Si ese cambio se extiende - por ser la institución inútil o inservible o porque la competencia entre las instituciones descubre aplicaciones más útiles- las malas instituciones, fruto de los errores de la acción humana, tenderán a desaparecer. Por el contrario, las buenas instituciones - las que son útiles- perdurarán como guía de la acción humana y, en buena medida, colaborarán en la minimización de sus errores ${ }^{5}$.

Baste esto para refutar la afirmación frecuente de que el Estado es una «institución» fruto de la evolución espontánea de las sociedades ${ }^{6}$. Podemos creer que el Estado resulta necesario, pero no que sea una institución. Primero, porque sus leyes y su composición sí son fruto de la consciente planificación de una persona o grupo de personas (los redactores de la parte orgánica de las Constituciones); segundo porque el Estado paraliza la evolución espontánea de prueba y error y no se autocorrige ${ }^{7}$; ter-

5 La institución del lenguaje, por ejemplo, minimiza los errores en la comunicación. De esta manera, los acuerdos entre las partes se vuelven más fiables y el nivel de certidumbre del actor aumenta. La institución del Derecho, paradigmáticamente, nos ayuda a discriminar entre acciones legítimas e ilegítimas y, en caso de que no estemos en presencia de legislación estatal, a poder emprender nuestros proyectos con mucha mayor seguridad de no equivocarnos.

6 Para una defensa de esta tesis, véase Raimondo Cubeddu, Atlas del Liberalismo, Unión Editorial, 1999, págs. 90-93. El problema principal que presentan este tipo de razonamientos es su incapacidad para discriminar entre las instituciones y el resto de la realidad circundante. En efecto, desde un punto de vista reduccionista toda la realidad es fruto de la evolución. Llamar al Estado institución implica creer que todo lo que proviene de la evolución es una institución, cuando ésta es una característica necesaria pero no suficiente.

7 Las acciones del Estado o bien son un acierto global o bien un error global; no se produce ninguna competencia descentralizada entre los agentes. Esto implica que las actuaciones del Estado se corresponden más con un modelo de actuación individual (elección y error) que con las sinergias institucionales. Es decir, la institución no se adapta continuamente a las necesidades de las personas, sino que son éstas 
cero, porque la falta de voluntariedad implica, en muchos casos (especialmente en el de los contribuyentes netos), una disminución de su utilidad; cuarto, porque el Estado sí lleva incorporado en su propia lógica constructivista la posibilidad e incluso conveniencia de cambiar unilateralmente sus pautas de actuación; y quinto porque, en resumen, no coordina a los individuos (sino que más bien los descoordina) y los dirige hacia el fin común establecido por los políticos.

\section{Fundamento de las instituciones}

Atendiendo al carácter no planificado de las instituciones, parece evidente que éstas se desarrollan de manera no intencionada sobre lo que podríamos denominar un «fundamento» o una «infraestructura».

Por fundamento de la institución entenderemos aquella característica sin la cual la institución no puede surgir o proseguir existiendo. Por supuesto, podría pensarse que las instituciones surgen y se reproducen por simple casualidad, sin que se apoyen sobre ningún tipo de base. Pero en este caso, todas las instituciones serían indistinguibles y no prestarían función singular alguna.

Para conocer cuál es la infraestructura de las distintas instituciones deberemos extender y aplicar lo que Ludwig von Mises llamó «teorema regresivo», esto es, retrotraer la institución hasta el momento en que no existía y estudiar cuál es el elemento fundamento ${ }^{8}$.

las que interiorizan sus errores. Dicho de otra manera, si bien los errores de los individuos enriquecen a la institución (pues la purga, la modifica, y la adapta), el error del Estado nos empobrece a todos. Por otro lado, el componente centralizador del Estado, como ya apuntara Mises, nos permite concluir que el Estado sólo puede fracasar.

8 Mises aplicó este teorema sólo al caso de la institución del dinero y llegó a la conclusión que el dinero surgía a partir de la intensa demanda sobre un bien que todavía nadie había concebido como medio general de intercambio. Por tanto, el sustrato de la institución del dinero está en la liquidez. 


\section{Primera manifestación}

Una vez la institución se ha desencadenado sobre su fundamento llega el momento en que los individuos la reconocen como tal; es decir, cuando los individuos se dan cuenta de que las consecuencias no intencionadas de sus acciones han engendrado una realidad que, empleada correctamente, puede ser útil para sus fines.

Mientras que el fundamento no llega a ser institución, sino sólo su presupuesto, la primera manifestación consiste en la utilización consciente que los individuos hacen de las pautas e instrumentos que han generado sobre esa infraestructura.

\section{Desarrollo}

La evolución ulterior dependerá de las distintas acciones de los individuos, esto es, de sus errores, de sus aciertos y de cómo ellos mismos reconozcan e interioricen esos errores y aciertos.

Los errores pueden reconocerse como tales y solucionarse (en cuyo caso se generan mecanismos preventivos y represivos para no volverlos a cometer); o, aunque se reconozcan, no saber solucionarse (en cuyo caso se adoptaran mecanismos defensivos para esos errores irresolubles). Pero también pueden no reconocerse y perpetuarlos hasta que conduzcan a la crisis de la institución (que comentaremos en el siguiente epígrafe).

Los aciertos pueden reconocerse y consolidarse (de modo que se generalizan y se incorporan en la institución); o pueden reconocerse pero sin ser capaces de reproducirlos en más ocasiones (en cuyo caso se genera un proceso de investigación o una desviación hacia acciones similares) o pueden confundirse con errores (de modo que su descubrimiento exitoso vuelve a quedar latente pero podría incluso dificultarse por la creación de mecanismos defensivos contra esas acciones). 


\section{Crisis}

Cuando en una sociedad los fundamentos de las instituciones son sistemáticamente atacados, ésta entra en crisis. La institución no puede seguir evolucionando correctamente si su soporte desaparece.

La crisis aparece cuando la institución ha incorporado en su estructura tal cantidad de errores que ya no sirve para satisfacer los fines humanos. En este contexto, la institución sólo puede «sanearse» a través de un período de catarsis masiva que en ocasiones puede conducir incluso a su completa desaparición.

Es importante darse cuenta de que las crisis pueden retrasarse notablemente si el ataque al fundamento de la institución se va difuminando con la participación de otras instituciones no corrompidas. En efecto, si la interrelación de instituciones puede proporcionar a los individuos una utilidad que aun no esté completamente desplazada por los instrumentos erróneos generados hasta el momento, los ataques al fundamento de la institución podrán continuar por más tiempo hasta que terminen de corromper la nueva institución.

A la explicación de este fenómeno la llamaremos teorema progresivo 9 .

II.

LA INSTITUCIÓN DEL DERECHO

En este apartado vamos a tratar de aplicar todas las conclusiones teóricas anteriores al caso de la institución del derecho entendida como un orden espontáneo de normas jurídicas que

\footnotetext{
9 Con clara influencia en el teorema regresivo de Mises, el teorema progresivo fue propuesto ochenta años después por el profesor Salerno, pero también aplicado al dinero: «El teorema asegura que los problemas inherentes a la reserva fraccional no pueden ser resueltos a través de ningún medio técnico como un fondo común de reservas, seguros de depósito, cláusulas de opción de redención... Estos mecanismos sólo trasladan el problema a otro nivel y, al mismo tiempo, lo empeoran. La única solución real pasaría por abandonar totalmente la reserva fraccionaria». Salerno, Jospeh, «Two Traditions in Monetary Theory", Journal des Économistes et des Études Humaines 2, n.ํ2 2/3 (1991): 37.
} 
emergen de la interacción humana y la compararemos con la organización estatal como productor de legislación.

\section{Nacimiento}

Cuando el ser humano se sitúa en el intercambio autístico, no se precisa ninguna norma jurídica. Éstas sólo son necesarias cuando los seres humanos se relacionan entre sí. Es improbable que alguna vez en la humanidad haya nacido un ser humano completamente autístico, toda persona nace en el seno de una familia y de una sociedad. Sin embargo, como hipótesis puede resultar interesante estudiarlo, es decir, retrotraernos a una situación robinsoniana para estudiar el surgimiento de las primeras pautas jurídicas.

Parece claro que el punto de partida del derecho está en la necesidad de resolver los conflictos de intereses que existen entre los individuos de una sociedad. Y parece claro que para dar solución a un conflicto primero tiene que surgir. Si un individuo pretende apropiarse de unas pieles de oso de otro individuo, pero éste muestra su consentimiento, ningún conflicto emerge. Ahora bien, si el individuo lo hace sin su consentimiento, es posible que comience una lucha entre ambos.

En este sentido, entre dos individuos con una fuerza semejante, ante las recurrentes escaramuzas, pronto operará la regla tácita de que nadie de los dos debe atentar contra la libertad y la propiedad del otro. Es decir, se establecerá el respeto mutuo a la libertad ajena siempre que no atente contra la mía. Tendremos un embrión de norma jurídica tácita.

Por supuesto, que dos individuos tengan la misma fuerza es poco frecuente, pero aun ante la disparidad de poder, el débil podrá recurrir a tres mecanismos para lograr defender su libertad.

a) Asociaciones de individuos inferiores en tribus o clanes: El poderoso fácilmente puede verse superado por «acuerdos de ayuda y defensa mutua» entre individuos, a pesar de que sean más débiles que él por separado. De esta forma, aparece una nueva norma jurídica (contrato interno entre los miembros de una tribu destinado a protegerse entre sí). 
b) El nomadismo: Si bien una de las razones por las que los primeros pueblos eran nómadas la encontramos en la insuficiente acumulación de capital, lo cierto es que el nomadismo tiene importantes ventajas a la hora de conseguir la paz social.

Cuando un individuo carece de propiedades inmobiliarias, las facilidades para huir y escapar del más fuerte son mucho mayores. Aquel individuo que quisiera imponer su fuerza y esclavizar o expoliar a otro, se encontraría, de repente, solo. Es decir, no tendría a nadie de quien nutrirse, pues todos los otros individuos huirían.

De esta manera, aunque a corto plazo pueda parecer preferible el expolio a las relaciones voluntarias entre individuos, sin duda éstas son preferibles al intercambio intrapersonal. La repetición del expolio genera incentivos al nomadismo y, por tanto, a abandonar a los más violentos. El simple interés propio induce a respetar las vidas y las propiedades de los demás.

c) La incertidumbre: Por último, hay que mencionar el elemento de la incertidumbre. El resultado de la acción humana es inherentemente incierto; las personas no pueden conocer ex ante si vencerán o perderán la batalla. De ahí que muchas decidan no asumir el elevado riesgo que podría suponer perder una guerra.

La lógica precaución puede llevar a un individuo a preferir la paz a la guerra, aun cuando su bienestar hubiere aumentado en caso de ganarla. Lógicamente, el incremento de los contratos de asistencia mutua supone un aumento de la incertidumbre por cuanto el resultado final de las batallas, al incrementar el número de participantes, se vuelve menos previsible.

Hay que recordar que la incertidumbre de una guerra es una incertidumbre pura, esto es, que no puede eliminarse con un mayor conocimiento de la acción humana ni de las condiciones de la misma. Sin duda, conocer el tipo de armamento o la estrategia del rival reduce la incertidumbre, pero no puede eliminarla por entero, por cuanto depende de acciones humanas no previsibles. No se pueden anticipar las heroicidades, los errores que se convierten en aciertos o las contraestrategias 
del rival. En otras palabras, no existe una decisión ex ante acertada, pues el resultado final no es anticipable.

En todo caso, debemos darnos cuenta de que las normas jurídicas sólo emergerán una vez alcanzada una mínima paz social, lo que resulta equivalente a respetar la libertad y la propiedad de aquellos individuos que vayan a ser partícipes en la institución del derecho. Sin ese respeto mutuo, en realidad, no emerge norma jurídica alguna, pues los derechos y obligaciones de una parte dependen exclusivamente de la voluntad de la otra. No existe reciprocidad, sino sólo sumisión.

Por ejemplo, los acuerdos de defensa mutua de los que ya hemos hablado son unos acuerdos jurídicos donde ya se presupone la libertad del resto de las partes y que se constituyen con la finalidad de que continúen siéndolo. Pero mientras no se logre ese mismo reconocimiento con respecto a otros clanes beligerantes, no habrá relaciones jurídicas entre ellos.

En definitiva, la necesidad de proteger nuestra libertad y nuestra propiedad favorece la aparición de instituciones, acuerdos y normas jurídicas dirigidos hacia este objetivo; es decir, instituciones que hagan que el comportamiento previsible ajeno no sea la iniciación de la violencia.

Cabe concluir que la propiedad no es por tanto una consecuencia del derecho, sino el requisito para que emerja. Sin la creencia y el deseo de conservar nuestra libertad y nuestra propiedad, no tendríamos ningún incentivo para protegernos o huir de los agresores. Y sin estos requisitos ninguna pauta jurídica puede surgir, salvo la imposición continuada de la voluntad del más fuerte ${ }^{10}$.

10 «Para una facción, la propiedad es infraestructura. Es endógena, aparece en todas las sociedad humanas, desde los moradores de las cavernas en adelante, y la ejecución del respeto a la propiedad es tan vieja como la humanidad (o, como algunos estudiantes de primates han descubierto, más vieja). Una propiedad razonablemente segura y su consecuencia, el comercio, son, para esta visión, anteriores a la autoridad política, al estado y al sistema legal centralizado.(...) Para la visión opuesta, la propiedad es una superestructura que debe su existencia a un mecanismo de ejecución elaborado por la sociedad y que opera bajo el Estado. El Estado, el sistema legal, las leyes contractuales y otras «instituciones de mercado», constituyen la infraestructura sobre la que la superestructura de la propiedad y el mercado 
El fundamento de la institución del derecho sería, de este modo, la autonomía de la voluntad entendida como la capacidad de decisión última (o propiedad) sobre nuestros bienes, incluido el propio cuerpo ${ }^{11}$.

\section{Primera manifestación}

Una vez se ha consolidado un cierto respeto por la propiedad los individuos puede colaborar y cooperar entre ellos para lograr sus fines. La división del trabajo y el intercambio son ejemplos de cómo los individuos aúnan esfuerzos en busca de su particular bienestar.

La noción del derecho comenzaría cuando se toman acuerdos y compromisos entre las partes con el ánimo de colaborar, esto es, de crear una reciprocidad de derechos y obligaciones mutuamente beneficiosa ${ }^{12}$.

El primer intercambio de esos derechos y obligaciones tuvo que adoptar la forma de acuerdos informales entre personas de confianza (familiares o amigos). El contrato de sociedad en el derecho romano ilustra perfectamente este punto. La sociedad

se construyen. La propiedad es un privilegio social, su inviolabilidad no puede invocarse en contra de la sociedad en sí misma, quien puede modificar o retirar los derechos de propiedad que ha garantizado y protegido». Anthony de Jasay, Justice and its Surroundings, Liberty Fund, 2002, págs. 6-7.

11 Al utilizar el término propiedad para explicar el origen del derecho podría pensarse que ya estamos haciendo referencia a una norma jurídica anterior que defina las atribuciones de la propiedad; sin embargo, como ya expliqué en otro sitio: «El derecho de propiedad concede a su titular una capacidad de decisión última sobre el objeto de la jurisdicción dominical. El propietario puede poseer, usar, consumir, destruir o enajenar el objeto sin que ningún otro sujeto tenga poder para revocar su decisión.(...) Una cosa es que los individuos tengan prohibido ejercer el derecho de propiedad y otra, muy distinta, es que este derecho de propiedad absoluto no sea ostentado por nadie. Por necesidad fáctica, siempre existirá un poder de decisión última sobre los recursos». Juan Ramón Rallo, Una Sociedad de Precaristas, Instituto Juan de Mariana: http:/ / www.juandemariana.org/comentario/447/

12 El art. 1088 del Código Civil español lo expresa con suficiente claridad: «Toda obligación consiste en dar, hacer o no hacer alguna cosa». En otras palabras, todas las obligaciones y los derechos recaen sobre la libre disposición de nuestras propiedades y de nuestras acciones. 
privada se asentaba en la confianza ${ }^{13}$ y la fraternidad ${ }^{14}$ de sus socios $^{15}$; por tanto, sin confianza esa sociedad quedaba extinguida $^{16}$.

El mecanismo para reproducir esos pactos entre personas con las que no se tuviera una confianza precedente pasaba por tratar de afianzarla a través de distintos mecanismos, el primero de los cuales fue el juramento ${ }^{17}$. Si el juramento se violaba, no sólo se perdía la reputación en la palabra dada, de manera que se paralizaban los acuerdos futuros que hubieren sido mutuamente beneficios, sino que además solía atentarse contra alguna divinidad.

\section{Desarrollo}

Con todo, en sí mismo el juramento es un mecanismo bastante ineficiente para hacer autoejecutables los acuerdos, por lo que cuando se reconoció su error o insuficiencia se fueron generando empresarialmente nuevos instrumentos que dieran respuesta a esta necesidad.

Por un lado, cabe hablar de los mecanismos preventivos, es decir, que el propio contrato contemple algunas cláusulas que

13 «La sociedad privada consiste en la creación de una comunidad de derechos sobre la base de un convenio de confianza libremente acordado por los socios». Derecho Privado Romano, Álvaro D’Ors, Ediciones Universidad de Navarra, 1997, página 542.

14 Así, en el Digesto 17, 2,63 podemos leer: cum societas ius quodammodo fraternitatis in se habeat. En cierto modo, vemos que la relación de confianza tuvo que nacer en el núcleo familiar (o tribal), hasta el punto de que la jurisprudencia romana seguía equiparando la familia con el ideal de sociedad privada. Es más, el derecho español, exige la custodia de las cosas con la diligencia propia de un buen padre de familia. (art. 1089 del Código Civil)

15 «La atracción social (gustar, generosidad, amistad) inicia y mantiene la cooperación; es una disposición a ofrecer un favor a quien te gusta y se dirige hacia quienes parecen dispuestos a devolver algo». Francisco Capella, Emociones (http:/ / www.intelib.com/Emociones.htm).

16 «Todo contrato de sociedad (...) debe cesar tan pronto cesa la confianza entre ellos [los socios]». Derecho Privado Romano, Álvaro D'Ors, Ediciones Universidad de Navarra, 1997, página 547.

17 «La etimología de ius (...) está en relación evidente con ius-iurare, "jurar"». Ibídem, pág. 43. 
penalicen al incumplidor o a un tercero. Sería el caso de las garantías reales y los fiadores.

Las garantías reales son, básicamente, la prenda y la hipoteca. Para garantizar el cumplimento de los contratos, una parte puede traspasar a la otra la posesión de un objeto más valioso que el de evitar el beneficiarse por incumplir el contrato. En esos casos, es evidente que no existe ningún incentivo a convertirse en free-rider.

Los fiadores son personas que se obligan en caso de que una de las partes no cumpla. Siendo ello así, es evidente que el desarrollo del sistema bancario juega un papel esencial. El banco puede convertirse en fiador de una de las partes, reteniendo un montante equivalente en concepto de depósitos ${ }^{18}$.

Ahora bien, es evidente que la existencia de estos mecanismos preventivos supone costes adicionales para las partes. Por un lado, obliga a perder la posesión durante un período de tiempo de una cosa o a tener inmovilizada una cierta cuantía de dinero en el banco. Por otro, las transacciones se ralentizan. Por no hablar de toda aquella gente que, por el motivo que sea, es incapaz de conseguir en ciertos momentos prendas o fiadores que avalen su credibilidad. En este sentido, los mecanismos preventivos constituían simplemente los precedentes necesarios para que, ante la repetición del juego, las partes adquirieran y basaran sus contratos, nuevamente, en la confianza.

Así, una vez las relaciones se vuelven a basar en la confianza ésta supone un activo para cada parte. Como hemos dicho, si no existe confianza deberán ofrecerse costosas garantías. Por tanto, defraudar en un juego supone incurrir en mayores costes en el siguiente.

Otra serie de respuestas contra el fraude la constituían los mecanismos represivos. El primero de ellos consistiría en, como ya hemos dicho, soportar los costes de las garantías.

18 Como explica Bruce Benson en relación con el crédito mercantil: «Había terceros (los bancos, por ejemplo) que facilitaban crédito a los compradores, y se desarrollaron instrumentos como la prenda hipotecaria para proteger a los acreedores del impago por parte de los deudores. De esta forma, los acreedores se aseguraban de que, si no se les reembolsaba su crédito, podrían vender la prenda para cobrar». Bruce Benson, Justicia sin Estado, Unión Editorial, 2000, pág. 49. 
El segundo, mucho más radical, pasa por la exclusión social ${ }^{19}$ del defraudador ${ }^{20}$. No consiste solamente en añadir costes a las transacciones futuras, sino en impedir incluso incurrir en ellas $^{21}$.

Así pues, es posible que los defraudadores tuvieran que renunciar a cualquier acción que implicara el uso de capital inmovilizado, esto es, allí donde la rentabilidad y los pagos no fueran absolutamente líquidos. En otras palabras, deberían convertirse en trabajadores y abandonar su actividad empresarial. Se produce una purga entre buenos y malos empresarios a través de las instituciones jurídicas.

Muchos son los que hoy en día consideran al Estado como la evolución definitiva de estos mecanismos preventivos y represivos para lograr la ejecución de los acuerdos contractuales. Sin embargo, ya hemos explicado por qué el Estado no puede considerarse como parte de esta institución.

En los siguientes epígrafes compararemos el funcionamiento de un derecho descentralizado o policéntrico que surja de la evolución espontánea frente al de una serie de mandados centralizados que pretendan suplantarlo.

19 «El tramposo puede perder mucho si su trasgresión se hace pública y se le excluye de la cooperación social; la culpa motiva una confesión sincera antes del descubrimiento del hecho como una demostración de arrepentimiento que puede ayudar a obtener el perdón (especialmente si el daño puede ser reparado)». Francisco Capella, Emociones, cit.

${ }^{20}$ Volviendo al caso de las sociedades romanas, es curioso que el quebrantamiento doloso de la confianza de los socios (certificada a través de la condena por la actio pro socio) suponía, especialmente, la inclusión de una nota social de infamia, lo cual se configura claramente como un mecanismo de exclusión social.

21 «La fuerza ejecutiva de las sentencias se basaba en la amenaza de exclusión social, una medida de presión muy efectiva. Si un tribunal de mercaderes dictaminaba que un mercader residente en Londres habría incumplido un contrato con otro de Colonia celebrado en la feria de Milán, por ejemplo, el mercader londinense tendría buenas razones para pagar la indemnización que el tribunal juzgara apropiada. Si no lo hacía, los demás mercaderes jamás volverían a hacer tratos con él». Bruce Benson, Justicia sin Estado, Unión Editorial, 2000, pág. 46 


\section{Características del derecho descentralizado u orden policéntrico}

Un orden policéntrico es una suma de muchos centros de jurisdicción. La primera cuestión a dilucidar será cuál es el centro jurisdiccional que tomamos como referencia.

Por jurisdicción entendemos la capacidad de decisión última de un individuo sobre un recurso escaso o, más en general, sobre un medio. Es importante que se trate de un medio económico (esto es, un recurso escaso) para poder hablar de jurisdicción ya que, en caso contrario, no estamos ante decisiones últimas. Lo que no es escaso, es infinito (al menos para los propósitos en consideración) y, sobre lo infinito, no cabe por definición una última decisión. Es decir, no hay decisiones conflictivas por las que una debe prevalecer sobre la otra. Por tanto, estamos hablando de centros de poder último sobre medios económicos.

Así mismo, al hacer referencia a las «decisiones» (poder jurisdiccional) y a los «medios económicos» (objeto sobre el que recae la jurisdicción), necesariamente estamos presuponiendo la idea de acción y, en concreto, de acción humana. Sólo el ser humano actúa, esto es, toma decisiones que conciernen a medios económicos. Esto significa que el poder jurisdiccional, necesariamente, deberá ejercerlo un ser humano.

Ya tenemos, pues, la primera estructura: ser humano $\rightarrow$ decisión $\rightarrow$ medio económico, que se corresponde con «órgano jurisdiccional» $\rightarrow$ «poder jurisdiccional» $\rightarrow$ «objeto de la jurisdicción».

De esta manera consagramos dos principios como bases del derecho espontáneo: la libertad y la propiedad privada. La libertad sería la condición de órgano jurisdiccional y la propiedad privada, los medios económicos sobre los que se ejercería la jurisdicción, esto es, sobre los que se tendría una capacidad de decisión última. Esta conclusión es idéntica a la que ya habíamos alcanzado cuando hablamos del fundamento de la institución del derecho.

Las normas en el orden policéntrico surgen de la interacción de los agentes. Dado que cada centro jurisdiccional es soberano, podrá lícitamente decidir no mantener relaciones con ningún otro centro jurisdiccional. Sin embargo, habida cuenta de las 
ventajas de la división del trabajo, del comercio, y de la escasez de recursos, la pauta será que todos los órdenes jurisdiccionales se relacionen entre sí.

Para ello será necesario establecer normas expresas (pactos o convenios) donde se establezcan claramente las condiciones del trato $^{22}$. Si, por ejemplo, el sujeto A quiere entrar en un territorio bajo jurisdicción de $\mathrm{B}, \mathrm{A}$ deberá someterse a las normas que haya pactado con B. Esto no significa (ni siquiera cuando A se quedara a vivir en territorio de B) que hayamos abandonado el orden policéntrico, siempre y cuando siga siendo posible que $B$ aparte a A o que A se separe de B.

Estas normas convencionales, además, entran en un proceso competitivo por alcanzar los fines de los órganos jurisdiccionales. Cuando una norma sea, finalmente, la que mejor permite satisfacer sus fines el individuo establecerá como fija esta regla. Esto provocará que otros individuos que tengan unos fines similares a los suyos puedan observarlas, adopten esa misma norma «eficiente»; con el resultado final de que la «buena norma» comenzará a extenderse en aquellas unidades jurisdiccionales que tengan fines similares.

En un orden policéntrico, se establece una experimentación individual de las mejores normas (es decir, de los mejores modos de relacionarse con los demás centros jurisdiccionales) y, al mismo tiempo, una competencia entre las diversas normas eficientes para alcanzar los respectivos fines ${ }^{23}$.

Algunas de estas normas eficientes, de hecho, pueden ser tan útiles (es decir, apropiadas para los fines de mucha gente) que se generalicen por todo un territorio ${ }^{24}$, adquiriendo una

22 Estos pactos podrán ser simples contratos de adhesión («quien entre en mi propiedad deberá acatar las siguientes normas») o contratos ad casum.

23 «El hecho no se convertirá en derecho porque una voluntad política se apropie de él después de hacer constar su coherencia con determinados valores que ella estima relevantes, o sea, después de una criba filtradora totalmente confiada a aquella voluntad. El hecho aquí es ya derecho por su fuerza intrínseca, desde el mismo momento en que ha demostrado la propia eficacia, o sea, la capacidad que encuentra en sí mismo para incidir de forma duradera sobre la experiencia». Paolo Grossi, El orden jurídico medieval, Marcial Pons, 1996, pág. 75.

24 Por ejemplo, «quien entre en mi propiedad no deberá destruir nada sin consentimiento del propietario». 
naturaleza global ${ }^{25}$. Cualquier individuo que quiera entrar en tal región, se someterá necesariamente a esa norma.

No es necesario, claro está, que esa generalización tenga un alcance territorial. En ocasiones, ciertas normas se extenderán entre los individuos que ejerzan una determinada profesión (lex mercatoria) o practiquen un cierto culto (derecho canónico). En estos casos, hablaremos de una costumbre regional, profesional o religiosa. No sólo eso, una misma persona podrá sujetarse a distintas normas cuando actúe en distintos ámbitos (por ejemplo un comerciante católico estaría sujeto a ambos derechos consuetudinarios).

Dada la notable generalización de determinadas normas entre los miembros de una profesión esta norma se hará cierta y previsible. No será necesario que cada individuo se informe de las normas concretas que le resultan aplicables en cada situación particular, bastará simplemente con que cada persona sepa con quién se está relacionando. De hecho, en caso de que un sujeto no se someta a una determinada costumbre, se preocupará por «romper la apariencia jurídica» y anunciar anticipadamente - con certeza y previsibilidad-que no se somete a ese ordenamiento ${ }^{26}$. De esta manera, las normas de un orden policéntrico cumplen con el principio de certeza, tanto en su acepción griega como romana ${ }^{27}$.

Los pactos pueden estar obviamente escritos y, en todo caso, la costumbre será una generalización de esos pactos escritos; por tanto, cumplen con la certeza a corto plazo. Por otro lado,

25 «El así llamado «Derecho vulgar» es, por ello, un filón alternativo: se trata de instituciones viejas que se deforman, instituciones nuevas que se crean, mediante una libre extracción del gran aljibe de la vida cotidiana». Paolo Grossi, El orden jurídico medieval, Marcial Pons, 1996, pág. 71.

26 Otro asunto es que al no someterse al ordenamiento general sea excluido de las relaciones con otros órganos jurisdiccionales. Por ejemplo, el mercader que no acate el derecho mercantil terminará sin relacionarse con ningún otro mercader. Todo ello no significa que el derecho se cristalice, ya que los cambios graduales que se introduzcan contarán con la aquiescencia del resto de sujetos en caso de que supongan una mejora para la consecución de sus fines.

27 «La concepción griega de la certeza de la ley era que fuera una ley escrita (...) podríamos denominarla una certeza a corto plazo de la ley. (...) Los romanos aceptaban y aplicaban un concepto de certeza de la ley que podría ser descrito como que la ley nunca debía someterse a cambios repentinos y no predecibles. (...) Éste es un concepto a largo plazo». Bruno Leoni, Freedom and the Law, Liberty Fund, 1991, págs. 50. 
al globalizarse esas normas consuetudinarias, nadie tiene el poder para modificarlas unilateralmente salvo en su jurisdicción (y, en todo caso, deberá modificar las normas con suficiente anticipación para que el resto de individuos que se relacionan con él sean conscientes del cambio).

Podemos comprobar rápidamente que todas estas características están presentes en el caso de la institución jurídica de un orden policéntrico: a) Nadie ha extendido conscientemente los contratos - ni su objetivo era el de crear normas generalessino que provienen de una competencia entre normas que generaliza las más útiles para los fines de los distintos individuos ${ }^{28}$; b) Este proceso de competencia está antecedido, como ya hemos visto, por un proceso de prueba y error individualizo consistente en buscar la mejor regla para las relaciones con el resto de individuos; c) Como hemos dicho, esas reglas deberán ser útiles para los fines de los individuos; d) Serán adoptados de manera voluntaria ${ }^{29}$, pudiendo no someterse a las mismas; y e) Son estables en tanto nadie tiene la capacidad para modificarlas a su antojo $^{30}$, debiendo advertir a los demás del cambio de regla.

La cuestión es cómo un orden policéntrico puede lograr autocorregirse sin ningún mecanismo exógeno que modifique globalmente las normas.

28 Esto establece una diferencia esencial con respecto a la legislación estatal. La legislación positiva lleva en sí misma el germen del cambio súbito. El derecho no es algo externo, sino algo que debe crearse. En ese sentido, es el propio individuo quien concibe las instituciones. Como diría Bruno Leoni acerca del derecho romano: «Nadie promulgaba la ley; nadie podía cambiarla a su propio arbitrio. Esto no significaba que no hubiera cambio, sino la certeza de que nadie se iba a la cama haciendo sus planes sobre la base de una regla actual para levantarse a la mañana siguiente y descubrir que esa ley había sido derogada por una innovación legislativa ». Ibídem, pág. 55.

29 «Un rasgo característico de estos procesos [el orden espontáneo jurídico] es que se realizan a través de la colaboración voluntaria de un enorme número de individuos cada uno de los cuales participa en el proceso de acuerdo con sus deseos y su habilidad para mantener o incluso modificar la condición actual de la economía, el lenguaje, la moda, etc...» Freedom and the Law, Bruno Leoni, Liberty Fund, pág. 95

30 Según Leoni, el hecho de que las normas no dependan de nadie en particular es otra forma de referirse a la certeza romana de las leyes o a largo plazo: «La ley nunca estaba sometida, como pauta general, a ningún deseo arbitrario o al poder arbitrario de una asamblea legislativa, o a una sola persona, incluyendo los senadores y otros prominentes magistrados del Estado». Ibídem, pág. 136 
Lo cierto es que, como ya hemos dicho, los ordenamientos jurídicos en competencia permiten seleccionar las normas más adecuadas para conseguir los fines de los sujetos.

De hecho, esta cualidad humana para buscar los mejores medios hacia sus fines es un proceso típicamente empresarial, tal y como describe el profesor Huerta de Soto ${ }^{31}$. Los individuos más perspicaces descubrirán de manera continuada ${ }^{32}$ las normas más eficientes para sus fines y este descubrimiento ${ }^{33}$ supone la generación de nueva información $n^{34}$, que podrá ser aprehendida y extendida por el resto de individuos ${ }^{35}$.

Pero además, los desajustes sociales supondrán oportunidades de ganancia para aquellos individuos que sepan y estén disgustos a corregirlos ${ }^{36}$. En el caso de órdenes jurisdiccionales múltiples, esto significa que, ante la existencia de conflictos entre dos órdenes jurisdiccionales (por ejemplo, en relación con la interpretación de las normas), podrán surgir empresarios dispuestos a arbitrar y corregir el desajuste interpretativo, de la manera más satisfactoria para ambas partes. Aquellos tribunales de arbitraje que aporten soluciones más creativas ${ }^{37}$, eficientes y adecuadas

31 La función empresarial es «la capacidad típicamente humana para darse cuenta de las oportunidades de ganancia que surgen en el entorno actuando en consecuencia para aprovecharse de las mismas». Jesús Huerta de Soto, «La Teoría de la Eficiencia Dinámica», Procesos de Mercado n.ำ 1, 2004

32 «El proceso empresarial jamás se detiene ni agota». Ibídem.

33 «La virtud ejemplar del Derecho Romano, por lo que debe seguir siendo estudiado en la actualidad, consiste en haber sido fundamentalmente un derecho científico, es decir, jurisprudencial, y no un orden impuesto por el legislador». Derecho Privado Romano, Álvaro D’Ors, Ediciones Universidad de Navarra, 1997, pág. 27.

34 «Todo acto empresarial supone el descubrimiento de una información nueva que antes no tenía el actor (una oportunidad de ganancia que previamente había pasado inadvertida). Esta información que constantemente crean los empresarios cuando actúan es subjetiva, práctica (en el sentido de que sólo se crea mediante el ejercicio de la acción empresarial en sus correspondientes contextos), dispersa (pues está diseminada en la mente de todos los seres humanos) y tácita (en el sentido de que es muy difícilmente articulable de manera formalizada)». Jesús Huerta de Soto, «La Teoría de la Eficiencia Dinámica», Procesos de Mercado n.o 1, 2004

35 «La función empresarial transmite información». Ibídem.

36 «Todo desajuste social se plasma en una oportunidad de ganancia que queda latente para ser descubierta por los empresarios». Ibídem.

37 «La función empresarial, por su propia naturaleza, es esencialmente creativa». Ibídem. 
medrarán a costa de los más torpes. Es más, a su vez, estas interpretaciones más eficientes pasarán a constituir jurisprudencia de referencia para los restantes tribunales de arbitraje y también pautas de comportamiento para el resto de órganos jurisdiccionales ${ }^{38}$.

Estamos ante un proceso de realimentación según el cual los mejores empresarios generan y extienden las mejores normas; discriminando, por su lado, a las malas normas, en un proceso descentralizado de prueba y error individualizado, que a través de la generalización de las buenas normas, provoca una mejora institucional, de la cual se benefician todos los sujetos que decidan libremente adscribirse. Esta mejora institucional permite utilizar nuevos instrumentos más eficientes para reducir los conflictos y así permiten un comportamiento más acertado de los individuos y, de nuevo, otra mejora institucional.

Las buenas normas dan paso a buenas acciones y las buenas acciones, a su vez, a mejores normas. Se trata de un círculo virtuoso encaminado a la minimización de los errores ${ }^{39}$.

Así pues, la competencia libre entre distintos órdenes jurisdiccionales da paso a una selección continua de las mejores normas ${ }^{40}$. Estas mejores normas impulsan y son impulsadas por la función empresarial ${ }^{41}$, esto es, el libre actuar de los órganos

38 «La función empresarial es coordinadora. Como consecuencia del acto empresarial que venimos describiendo, A y B aprenden a disciplinar o coordinar su comportamiento en función de las necesidades ajenas del otro». Ibídem.

39 El profesor Huerta de Soto acertadamente lo ha denominado «Big Bang social coordinado»: «el acto empresarial, a la vez que coordina, crea nueva información que a su vez modifica en el mercado la percepción general de fines y medios de los actores implicados, lo cual da lugar a la aparición de nuevos desajustes, que a su vez tienden a ser descubiertos y coordinados empresarialmente, y así sucesivamente a lo largo de un proceso que jamás se detiene de expansión sin límite del conocimiento y los recursos, apoyado sobre un volumen de población siempre creciente, y que tiende a ser tan coordinado como sea humanamente posible en cada circunstancia histórica». Ibídem.

${ }^{40}$ La Iglesia Católica también parece haber llegado a conclusiones similares a las de este círculo virtuoso: «En la medida en que el hombre hace más el bien, se va haciendo también más libre. No hay verdadera libertad sino en el servicio del bien y de la justicia. La elección de la desobediencia y del mal es un abuso de la libertad y conduce a "la esclavitud del pecado"»(cf Rm 6, 17), Catecismo de la Iglesia Católica, Libertad y Responsabilidad.

41 «La praxis construye día a día su Derecho, lo plasma y lo modifica según las exigencias de los lugares y los tiempos». Paolo Grossi, El orden jurídico medieval, Marcial Pons, 1996, pág. 80. 
jurisdiccionales. El orden policéntrico tiende a reducir los conflictos y a coordinar a los individuos al descubrir cuáles son las mejores normas para la sociedad ${ }^{42}$. Resulta claro que las normas de un orden policéntrico se autocorrigen, de manera que cumplen todas las características de una institución jurídica.

\section{Características de una organización jurisdiccional centralizada o monocéntrica}

Una vez concluido el estudio del orden policéntrico debemos abordar las características de la organización monocéntrica. En este caso, nos encontraremos ante un único poder sobre distintas personas; es decir, el órgano jurisdiccional será un individuo con características especiales que tomará las decisiones últimas sobre todas las propiedades y las personas que se encuentren dentro de su jurisdicción ${ }^{43}$; en otras palabras, los individuos pasan a convertirse en medios económicos del órgano jurisdiccional.

Pero además, hay que señalar que, a diferencia del orden policéntrico, en una organización monocéntrica la jurisdicción recae sobre los bienes económicos y sobre los llamados «bienes libres», esto es, aquellos sobre los que no existe disputa o conflicto.

Ya hemos dicho que, por definición en el orden policéntrico no caben decisiones últimas sobre bienes que no son escasos, esto es, que pueden ser usados por una infinidad de individuos. Con todo, la organización puede obligar a los individuos - objetos de su jurisdicción - a que actúen como si esos bienes libres fueran escasos.

42 En palabras de Bruno Leoni: «Tanto los romanos como los ingleses compartían la idea de que la ley era algo que debía ser descubierto más que promulgado y la de que nadie era tan poderoso en la sociedad como para identificar su propio deseo con la ley del territorio». Freedom and the Law, Liberty Fund, 1991, pág. 8.

43 Por supuesto, el rasgo territorial es importante, pero en absoluto distintivo. La organización monocéntrica adquiere carta de naturaleza cuando la capacidad de decisión última de un individuo no depende de sí mismo, sino de otra persona. Lo que caracteriza, pues, a la organización monocéntrica es que el ser humano actúa en una situación de precarista: sus decisiones, cualesquiera que sean, resultan revocables por decisión de un órgano jurisdiccional superior. 
Dado que el conflicto emerge de las relaciones humanas y dado que el Estado controla esas relaciones humanas, le resulta viable crear conflictos artificiales en relación con un bien libre y convertirlo en objeto litigioso. A partir de ese momento, el bien libre se convierte en escaso, de manera que el Estado puede ejercer su poder sobre el mismo.

El órgano jurisdiccional, por su parte, puede adoptar una gran variedad de formas: un único individuo, varios individuos, una asamblea, distintas formas según el ámbito de poder, o incluso la totalidad de las personas que, a su vez, son objeto de jurisdicción siempre que no exista el derecho de secesión o separación individual. Para simplificar llamaremos a ese órgano jurisdiccional, sea cual sea su forma, Estado.

La estructura de la organización monocéntrica sería similar a la ya vista con el orden policéntrico: Estado $\rightarrow$ decisión $\rightarrow$ medios económicos, incluyendo en estos últimos, individuos y bienes libres.

La mutación esencial que se produce en la transformación de un orden policéntrico a una organización monocéntrica es el paso de un sistema de normas generales donde todos los individuos pueden satisfacer sus fines a una maraña inconexa de mandatos donde los fines de unos individuos se imponen a los de otros individuos ${ }^{44}$.

Tal mutación podemos observarla perfectamente comparando las características de la institución jurídica espontánea con la legislación estatal:

44 «La ley en general empezó a ser concebida como el resultado de las decisiones del grupo en lugar de las elecciones individuales, y algunos teóricos como el profesor Hans Kelsen fueron lo suficientemente lejos como para negar que sea posible hablar incluso de comportamiento jurídico o político de unos individuos sin hacer referencia a un conjunto de normas a partir de las cuales el comportamiento pueda ser calificado de legal o no». Bruno Leoni, Freedom and the Law, Liberty Fund, 1991, pag. 95.

Kelsen, padre del positivismo contemporáneo, se incluye claramente entre aquellos individuos que consideran el sistema legal una superestructura necesaria para la aparición de la propiedad. Ya hemos demostrado en los apartados precedentes que, en cambio, como dice Jasay, la propiedad es la infraestructura necesaria para que emerja cualquier sistema normativo. Por tanto, los argumentos de Kelsen que denuncia Leoni carecen por entero de fundamento. 
a) Ausencia de autor o mente creadora concreta: Mientras que todo el sistema normativo policéntrico no ha surgido por la planificación consciente de nada; en la legislación estatal, los órganos jurisdiccionales organizan el territorio a través de una serie de mandatos coactivos. El sistema jurídico procede de la mente de un individuo o de un conjunto de individuos que crean las normas con voluntad universalista.

Todas las acciones individuales que coincidan con un determinado «supuesto de hecho» deberán, necesariamente, adaptarse al mandato estatal. No es posible otra previsión a menos que, de nuevo, el mandato estatal expresamente conceda un cierto grado de autonomía.

b) Continua evolución descentralizada de las mismas a través del mecanismo de prueba y error: En la organización monocéntrica, hay que hacer una distinción aparente. Por un lado, tenemos aquellos sistemas autocráticos donde los individuos que recaen en una jurisdicción son utilizados, sin ningún tipo de contemplación, como medios para los fines particulares del dirigente. Por tanto, el mandato coactivo pretende coordinar a los individuos para que trabajen en beneficio del dirigente. En este caso, el mecanismo de prueba y error está muy atenuado, por cuanto sólo un individuo -el órgano jurisdiccional- está legitimado para experimentar instrumentos normativos.

El segundo caso sería aquel donde los intereses de los dirigentes consisten en alcanzar el bienestar de los gobernados, esto es, existe una perfecta identificación entre los intereses del órgano jurisdiccional y de los individuos objeto de la jurisdicción ${ }^{45}$.

Los mandatos se conciben como medios para que los fines de los individuos obtengan cumplida satisfacción. En este caso, hay que decir que la experimentación queda totalmente paralizada. Por un lado, los individuos, cada individuo, no tienen capacidad para elegir unas normas y desechar otras, de manera que sus fines no vienen dados por el respeto a los

45 En términos neoclásicos, podríamos decir que la función de utilidad del dirigente es igual al sumatorio de todas las funciones de utilidad individuales. 
fines ajenos, sino por la acomodación a las normas establecidas desde arriba ${ }^{46}$.

El proceso de mercado y de experimentación se sustituye por el de buscar un nicho entre las normas. No hay manera de comprobar si una norma es buena o mala para conseguir los fines del actor, porque el actor sólo puede acceder a aquellos fines que la norma le deja acceder. Dado que el dirigente no puede conocer cuáles son los fines de cada individuo, será incapaz de comprobar y experimentar si una norma es buena o mala.

En realidad, pues, si un Estado pretende que todos los individuos sean capaces de lograr sus fines deberá retirar su estrecha regulación y permitir que sean los propios individuos quienes, libremente y de acuerdo con sus fines, se interrelacionen, dando lugar a distintas formas de regulación

c) Utilidad que le atribuyen sus participantes: La organización monocéntrica, como ya hemos visto, es el mecanismo por el que ciertos individuos imponen sus fines a los demás. En principio, pues, habrá participantes que le atribuyan utilidad y otros a los que se la reduzca. En tanto sea un mecanismo redistributivo, unos individuos ganarán y otros perderán.

d) La voluntariedad: La participación voluntaria de una institución estatal supondría su desaparición en la práctica. El Estado se basa en la filiación coactiva; en caso contrario, aquellos individuos explotados por leyes injustas se secesionarían del mismo.

e) La estabilidad: La misma concepción del Estado supone la capacidad unilateral para modificar todos sus mandatos. El

${ }^{46}$ Bruno Leoni nuevamente denuncia que cuando se elimina la evolución espontánea de las normas los abogados de la segunda generación (aquellos que no han conocido la institución espontánea) son incapaces de comprender el proceso de descubrimiento que supone el derecho. «Se acostumbran a referirse simplemente al código y no al trasfondo histórico». Bruno Leoni, Freedom and the Law, Liberty Fund, 1991, pág. 95

En otras palabras, el comportamiento de los «doctores» del derecho se convierte en recepticio o pasivo. Los abogados, tribunales y la doctrina en general abandona su posición típicamente proactiva y empresarial que hace avanzar al sistema jurídico. 
Estado puede, por su propia legitimidad, modificar las normas sin basarse en el derecho preexistente.

Esto significa que las normas por las que el actuar humano se rige hoy pueden ser radicalmente modificadas mañana y que, por tanto, el individuo no tenga la posibilidad de adaptarse.

Puede, por tanto, que las normas sean ciertas en un sentido griego (si bien la inflación legislativa provoca que, por muy escritas que estén las normas, el individuo sea incapaz de abarcarlas y conocerlas), pero en ningún caso existe certidumbre en sentido romano, esto es, a largo plazo. No hay modo de saber si lo que hoy es legal, lo será en el futuro y, por ello, la certidumbre del derecho es nula.

f) Autocorrección: Mientras que los individuos estén obligados a seguir los mandatos del gobierno, no podrán ejercer su actividad empresarial. El conocimiento deja de seleccionarse en términos de valor y simplemente se impone por la fuerza. De esta manera, se impide que los individuos descubran, a su vez, las necesidades insatisfechas de otras partes de la sociedad ${ }^{47}$.

El efecto de cada norma, de cada mandato debido, es restringir la creatividad y la coordinación empresarial. Si esa serie de mandatos se sitúan en ámbitos concretos de la acción humana, la parálisis se producirá de modo especial, pero no único, en esos ámbitos. La razón es que pueden seguir existiendo incentivos para participar en áreas reguladas por el gobierno, y al incrementar los costes en la misma, otras necesidades quedarán insatisfechas.

El caso límite del socialismo, donde todas las acciones se encuentran reglamentadas, implica que toda la selección de información se realizará arbitrariamente por el gobierno. Es más, se dejará de crear un gran volumen de información que no podrá ser descubierto por el gobierno.

47 «Es muy importante entender claramente que la agresión no sólo impide el aprovechar la oportunidad de ganancia, sino que impide incluso el descubrimiento de dicha oportunidad». Jesús Huerta de Soto, Socialismo, Cálculo Económico y Función empresarial, Unión Editorial, 1992, pág. 91. 
En otras palabras, los individuos no descubrirán continuamente las mejores normas, por lo que el gobierno no podrá copiarlas. Bien conocido es el caso de la codificación decimonónica en Europa, momento en el que los gobiernos recopilaron todo el derecho consuetudinario anterior y lo imprimieron en códigos nacionales.

Los juristas coinciden en considerar este proceso la petrificación de la costumbre, lo cual, a su vez, ha dificultado la actividad legislativa durante todo el siglo XX, en tanto el desfase temporal ha dificultado que los gobernantes tuvieran un espejo empresarial en el que mirarse. Su labor, con todo, no ha sido salvajemente constructivista pues todavía disponen de toda la sabiduría milenaria que supone la convergencia del derecho romano y canónico en el derecho común europeo.

Pero, en todo caso, es evidente que las normas jurídicas estatales paralizan la actividad empresarial al imponerles un curso de acción que libremente no habrían seguido y que, por tanto, les impide utilizar la información del mejor modo posible. En otras palabras, desde la perspectiva de la eficiencia dinámica los mandatos monocéntricos no contribuyen a un desarrollo eficiente de la institución jurídica.

\section{Crisis de la institución}

Como ya hemos visto, los mandatos estatales reprimirán seriamente la función empresarial, de manera que una buena porción de los individuos no podrá conseguir sus fines. De esto modo, podemos distinguir tres actitudes frente a la violencia estatal:

- Apoyarla por ser útil para mis intereses (grupo 1): Éste sería el caso de los políticos, los funcionarios, los «intelectuales orgánicos» y todo el resto de personas que viven de las subvenciones o de los privilegios del Estado (sindicatos, agricultores...). El Estado y el uso de la fuerza les permite vivir a costa de los demás. Por tanto, seguirán apoyando las políticas que les benefician a no ser que, por ejemplo, se convenzan de la 
inmoralidad de sus actuaciones y el ingreso monetario no les compense la insatisfacción psíquica.

- Apoyarla por creer que es útil a mis intereses (grupo 2): Este sería el caso de todos aquellos individuos que creen necesario al Estado para proporcionar el entramado jurídico e institucional ${ }^{48}$.

En este caso se encuentra la inmensa mayoría de la población en las sociedades occidentales. Actúan conforme a las pautas marcadas por el Estado porque creen que así -y sólo así- lograrán sus fines. También se encuentran en este grupo todas las personas que se acogen a intervenciones del Estado creyendo que son buenas para la sociedad, como por ejemplo, invertir con tipos de interés rebajados a través de la expansión crediticia ${ }^{49}$.

Mientras que el primer grupo vive del Estado y, por tanto necesita al Estado, este grupo vive creyendo que el Estado existe para su beneficio, cayendo en una profunda ilusión ${ }^{50}$.

- Rechazarla por violar mis intereses (grupo 3): En este grupo se encontrarían todas aquellas personas que no están dispuestas a acatar las normas por suponer una violación de su derecho de propiedad y de los fines que establece para su vida. Ahora bien, también podríamos incluir todas aquellas personas que actuaran en calidad de free-riders con el Estado, esto es, creyendo erróneamente que es necesario, pero que su no

48 «Los gobiernos siempre disfrutan de una gran ventaja: la presunción a su favor, esto es, la mayoría de las personas dirigidas cree que el gobierno es necesario para proveer ciertos servicios. En otras palabras, creen que una sociedad basada sólo en cooperación voluntaria no podría funcionar». Jörg Guido Hülsmann, «Political Unification: A generalized Progresión Theorem», Journal of Libertarian Studies, 13-1. Vemos como Hülsmann ha alcanzado conclusiones muy similares a las nuestras. Precisamente, nuestro primer cometido ha sido demostrar que la sociedad sí puede estar basada en instituciones cooperativas y, como decimos, la mayoría de defensores del Estado lo hacen aduciendo que es el único método que nos permitiría proveer justicia y seguridad.

49 «Si los bancarios que se acogen a la reserva fraccionaria no son penalizados porque los actores del mercado creen que sus negocios son legítimos, entonces hay, ipso facto, un gobierno». Jörg Guido Hülsmann, «Toward a General Theory of Error Cycles», Quarterly Journal of Austrian Economics, 1-4.

50 «Hay una institución envolvente en la que la ilusión es inherente. Esta institución es el gobierno; esto es, una persona o grupo de personas que violan permanentemente los derechos de propiedad de otra gente». Ibídem. 
observancia no daña sustancialmente al bienestar general y si incrementa el particular.

Hay que tener presente que estos grupos no clasifican a sujetos, sino a acciones individuales con respecto a ciertas normas. Un agricultor, por ejemplo, puede apoyar las subvenciones pero luego desconfiar del Estado y buscar su reducción en otros ámbitos. Un liberal, de la misma manera, puede defender la privatización de la educación, pero no de la justicia (por creer que contribuye al bien común).

La distinción nos interesa porque, dependiendo de la actitud, las personas reaccionarán de una forma distinta respecto a las normas. Cuando la gente siente que las normas están dictadas en su interés particular tenderá a defenderlas aun recurriendo a la manipulación y a la mentira. Si en cambio piensa que las normas contribuyen al bien común, la respuesta será desde una tímida indiferencia hasta una defensa razonada de las mismas; si bien es posible que termine dándose cuenta de su error cuando experimente el fracaso o métodos privados más eficientes. Por último, si los individuos creen que una norma es injusta y que atenta contra sus intereses tendrán incentivos para recurrir al mercado negro:

- Apología de las normas: Los grupos que viven del Estado serán los que de manera más activa colaborarán en justificar el régimen y en moldear el ordenamiento jurídico. Su función será aprobar normas que los sitúen a ellos mismos en el grupo 1 y propagarlas entre la población para que o bien se mantengan en el grupo 2 o pasen del grupo 3 al $2^{51}$.

51 «En todo momento y en todo lugar, los gobiernos tratan de persuadir a la gente de dos cosas: primero, que la resistencia no es un derecho del pueblo y, segundo, que un incremento de los impuestos es necesario o beneficioso». "Political Unification: A generalized Progresión Theorem», Jörg Guido Hülsmann. También: «La función de los ideólogos al servicio del Estado es tejer los falsos ropajes del emperador para inducir a los ciudadanos a la aceptación de un doble rasero: que cuando el Estado comete los más graves y execrables crímenes no hace en realidad tal cosa, sino que lleva a cabo una tarea necesaria, adecuada, vital, ejecutada incluso —en edades pasadas- por mandato divino. El éxito secular de los ideólogos del Estado es probablemente la más gigantesca trampa de la historia del género humano». Murray Rothbard, La Ética de la Libertad, Unión Editorial, 1995, pág. 234. 
Sobre el ordenamiento jurídico, la influencia de estas normas se traduce en inducir a la gente al error. Tratan de convencer a los individuos para que crean que el fin perseguido por las normas no sólo es posible sino que además les resulta útil. Sin embargo, en tanto éstos incorporen los mandatos gubernamentales a sus propios planes, sin tener en cuenta las contrapartidas y los costes no percibidos ${ }^{52}$ (tengamos presente que si esta gente creyera que los costes del mandato superan a sus beneficios, entonces integraría el grupo 3), habrán incurrido en un error que les impedirá completar sus planes ${ }^{53}$. Por tanto, este grupo será el inductor de los errores del segundo.

La actitud de estas personas, pues, no sólo provocará que los mandatos estatales interrumpan la consecución de los fines, sino que las actividades empresariales de los sujetos caigan en continuos errores.

- Acatamiento de las normas: Los individuos respetan las normas y creen que su comportamiento contribuye de manera conjunta al bien común. En estos casos las instituciones resultantes serán fruto del generalizado engaño de que el gobierno es necesario, esto es, de que resulta mucho más útil de lo que en realidad es. La gente hará previsiones de seguridad, resolución de pleitos, cumplimiento de los acuerdos, calidad educativa o estabilidad de precios, que no se cumplirán.

Estos comportamientos erróneos dan lugar a instituciones que también serán erróneas. Los comportamientos pautados

52 «Lo que quería señalar es que las decisiones de grupo se cree frecuentemente que cuestan mucho menos de lo que le parecería a un observador superficial». Bruno Leoni, Freedom and the Law, Liberty Fund, 1991, pág. 10.

53 «La víctima de un comportamiento fraudulento no se da cuenta de su comportamiento y, por tanto, actúa como si todo estuviera aun en orden. Piensa que puede realizar sus proyectos tal y como había planeado. No se ha dado cuenta de que la cantidad de sus medios ha disminuido. Por consiguiente, no ajustará la estructura de su propiedad a las nuevas circunstancias». Jörg Guido Hülsmann, «Toward a General Theory of Error Cycles», Quarterly Journal of Austrian Economics, 1-4. Por supuesto, la víctima de una agresión gubernamental podría llegar a ser consciente del coste de oportunidad de la actividad del gobierno (si bien, dados los sistemas fiscales actuales y el sinfín de regulaciones, tal posibilidad es casi imposible), pero, si permanece en el grupo 2, sobrevalorará la utilidad de los medios políticos, con lo cual cometerá un error tecnológico. 
que difundan estos individuos serán comportamientos que interioricen la restricción del mandato como adecuada para sus fines. Por ello, se producirá un error generalizado.

Lo significativo de este grupo es que a través de la prueba y el error puede pasar a integrar el tercer grupo, esto es, puede convencerse de que el gobierno va en contra de su interés. No obstante, los apologistas del gobierno consiguen que este grupo crea que, aun cuando sus planes hayan fracasado, sin la intervención estatal, el resultado habría sido todavía peor. De esta manera, la gente permanece en el grupo dos y los errores se vuelven recurrentes ${ }^{54}$.

Mientras el fraude permanezca las instituciones seguirán siendo erróneas. El problema no es tanto que una gente engañe a otra, sino que la gente desengañada sea perseguida o reeducada por el Estado para que no pueda mostrar a los demás su comportamiento más eficiente.

- Oposición a las normas: Con independencia de si la oposición a la norma procede del convencimiento de su injusticia o de un calculado interés en quebrantarla, lo cierto es que en principio la no sujeción a un mandato supone la experimentación con formas alternativas de resolver los problemas sociales. El problema es que, como en breve desarrollaremos, la sanción que todo Estado debe asociar a su mandato disuade en ocasiones una actitud de oposición a la norma y sobre todo hace que esa oposición y esas soluciones alternativas permanezcan ocultas y fragmentadas.

El resultado lógico del choque entre estas tres fuerzas debería ser, lógicamente, el de la victoria de la tercera. Por mucho que los aduladores del Estado difundieran el mensaje de que éste es imprescindible, los sujetos del segundo grupo se moverían rápidamente al tercero en tanto no alcanzaran el fin general y vieran que otros sí lo hacen.

Pero este resultado únicamente acaece cuando estamos en un orden policéntrico donde los errores se autocorrigen. En la organización monocéntrica, basada en la fuerza, los

54 «La teoría del ciclo económico no tiene que explicar solamente la ocurrencia del error, sino también la recurrencia de un cluster de errores». Ibídem. 
individuos del tercer grupo, como ya hemos comentado, son sancionados siempre que quieran experimentar nuevas normas.

Ahora bien, este uso de la coacción no le resulta gratuito al Estado. Toda sanción requiere del uso de la fuerza, es decir, de un incremento del intervencionismo practicado. Este intervencionismo adicional provendrá de tres vías: el incremento de la violencia necesario para aplicar las normas, la degeneración institucional (que irá reduciendo la utilidad de la institución jurídica como mecanismo de resolución de conflictos) y la cultura de la irresponsabilidad (la propagación de pautas violentas de conducta como reproducción y aprendizaje de las desarrolladas por el Estado).

Las instituciones jurídicas acaban corrompiéndose y quebrantándose, con lo que la degeneración del derecho alcanza el punto en el que la catarsis deviene inevitable ${ }^{55}$. De la misma manera que la crisis económica sigue a la inflación crediticia, la crisis social sigue a la inflación jurídica. Los individuos adoptan, en su caso, tres estrategias distintas frente al Estado que se corresponden con los tres recursos ya estudiados:

- Violencia interna: Cuando la agresión es contemplada como tal, diversos individuos decidirán organizarse y defenderse abiertamente del agresor. Así aparecen mafias o grupos independentistas que claman la jurisdicción sobre zonas de su territorio. El Estado debe desaparecer de esas zonas o el conflicto devendrá inevitable. El caso extremo sería el de la guerra civil, la batalla entre los que todavía no se han desencantado del gobierno contra los que pretenden sustituirlo. La institución jurídica en estos casos desaparece por completo, y sólo cuando la guerra termina los individuos supervivientes pueden volver a realizar acuerdos creíbles y promesas.

55 «Este ensayo ahondará en la posibilidad de que el esfuerzo para imponer un orden social pueda en realidad conducir al quebrantamiento del orden y de que cualquier estructura formal legal pueda contener elementos disfuncionales que lleven a ese resultado». Butler D. Shaffer, «La violencia como producto del orden impuesto», Libertas n.. 9, 1988. 
- Migraciones masivas (Nomadismo): Obviamente, en las sociedades modernas la práctica del nomadismo ha sido sustituida por las migraciones masivas. La parte de la población que ya ha comprendido la naturaleza asfixiante del Estado decide huir. Dado que tienen importantes riquezas en el territorio jurisdicción del Estado, se trata de una medida muy dolorosa y costosa que muy pocos están dispuestos a emprender.

Los efectos de las migraciones masivas son completamente desastrosos para una sociedad. En efecto, existen motivos para pensar que quienes primero abandonarán el país serán las personas más capaces, los mejores empresarios. Por un lado, serán ellos los que perciban un mayor coste de oportunidad por permanecer en un Estado absolutamente reglamentado; por otro, también tenderán a minimizar los costes de la migración, por cuanto su capacidad les permitirá «volver a empezar» en otras partes del mundo más libres.

La migración de las mentes más capaces y emprendedoras agravará la situación de atrofia institucional, requiriendo dosis mayores de intervencionismo.

- Sometimiento (Incertidumbre): Aun cuando sectores importantes de la población muestren su descontento con el gobierno, durante largos períodos de tiempo pueden considerar que no conviene sublevarse o migrar, bien porque los costes son muy elevados o porque el resultado también lo es. En estos casos, asistimos a un sometimiento o esclavitud voluntaria de los individuos. Se trata de una situación generalmente inestable que, en todo caso, terminará con algún tipo de revolución, que puede ser más o menos pacífica (como la ocurrida en los antiguos satélites de la URSS) o sangrienta (como ha sucedido con muchos procesos de descolonización en África).

Esto nos permite aplicar el teorema progresivo de las instituciones al caso del derecho lo que significa que necesariamente la institución sufrirá una profunda degeneración que acabará en una crisis catártica.

Además, también podemos concluir que si los Estados quieren mantener su monopolio monocéntrico — dado que 
no parece probable que logren someter a la población en la esclavitud al estilo de la URSS stalinista-, tenderán a recurrir a unificaciones políticas que amplíen sus jurisdicciones, bien a través de tratados internacionales o de la constitución de nuevos bloques estatales.

A través de la unificación política, los diversos Estados conseguirían hacer frente a la globalización y eliminar los perversos efectos para sus pretensiones dominadoras. En caso de llegar al supuesto extremo de un gobierno mundial, los individuos no podrían recurrir a las migraciones masivas como mecanismo de defensa. Todo el mundo estaría bajo un mismo mandato.

La institución jurídica sufriría una parálisis sin precedentes y los individuos deberían aceptar convertirse en esclavos del poder político, renunciando a sus vidas y a sus fines, o emprender guerras de liberación y secesión. En cualquier caso, la institución jurídica que favorece la cooperación y los acuerdos creíbles entre los individuos se quebraría y fragmentaría. Cuando el ataque a la propiedad privada se vuelve máximo - bien a través de la esclavización o de la guerra sin cuartel- la institución jurídica simplemente desaparece.

Por tanto, nuestro teorema progresivo del derecho sería el siguiente: todo ataque a la propiedad privada genera una degeneración de la institución jurídica; toda degeneración jurídica conducirá, en una organización monocéntrica, o bien a la destrucción completa de la institución jurídica (a través de la esclavitud de los ciudadanos) o bien a gobiernos cada vez mayores, pero que sólo servirán para aplazar la crisis de la institución ${ }^{56}$.

56 Hülsmann considera que la integración política es consecuencia inevitable de la progresiva insolvencia de los distintos gobiernos: «El hecho fundamental es que la mayoría de los gobiernos modernos están muy endeudados. Y no hay duda de que pagar las deudas resulta muy impopular por el incremento de impuestos que requeriría. Por tanto, hay sólo tres vías posibles, a saber: inflación, denunciar la deuda, y la unificación política(...) La tercera opción consiste en proporcionar liquidez de los gobiernos que todavía no hayan quebrado. El precio a pagar por esta asistencia es, por supuesto, en términos de favores políticos». Jörg Guido Hülsmann, 


\section{La teoría del desprendimiento}

Las organizaciones monocéntricas nos niegan el derecho de secesión, por lo que la única manera pacífica de defendernos consiste en la emigración, bien personal o bien de nuestras riquezas. Esta amenaza de migración no sólo mantiene contenida la rapiña estatal, sino que además permite el ejercicio de la función empresarial a escala internacional a través de las transacciones supraestatales ${ }^{57}$. Si las unificaciones políticas, los impuestos internacionales ${ }^{58}$ o la armonización internacional de normas se materializan, entonces el círculo vicioso se acelerará e inevitablemente provocaremos la destrucción de la institución jurídica, de la paz y de la prosperidad.

Sin embargo, la globalización permite resistir la inevitable degeneración de nuestra convivencia, ya que ayudar a entender que no necesitamos de una organización monocéntrica para sobrevivir. Cuanto más interactúen los individuos en el orden espontáneo internacional (en los mercados OTCs), más gente pasará del grupo 2 al 3 y, por tanto, más débiles serán las bases

«Political Unification: A Generalized Progression Theorem», Journal of Libertarian Studies, 13-1. Su tesis no es, en absoluto, incompatible con la nuestra. Nosotros hemos analizado la necesidad de una unificación política desde el punto de vista jurídico, sin embargo no dudamos de que las razones financieras impulsan también hacia ella. De hecho, la deuda de los gobiernos tiene su origen en su necesidad de mantener bajo control a la población, a través de controles policiales, educativos y económicos (por ejemplo, ninguna persona de 55 años en la Unión Europea sería tan insensata como para levantarse contra el Estado, arriesgándose a perder la única pensión de la que dispondrá durante el resto de su vida). Es más, Hülsmann ve claramente que un nuevo ataque a la propiedad privada desde el lado impositivo supondría o bien un levantamiento popular o una fuga de capitales que los gobiernos no están dispuestos a consentir. Por otro lado, una impresión masiva de dinero daría al traste con la institución monetaria. De ahí que la única solución para no desencadenar una crisis jurídica o una crisis monetaria pasa por la unificación política.

57 Que a su vez sirven como referencia para que los mandatos de los dirigentes no sean tan represivos para la función empresarial; tal y como sucedía con el Gosplan soviético que fijaba sus precios internos en función de los precios internacionales.

58 Por ejemplo, la famosa Tasa Tobin no es más que un intento de incrementar los costes de la migración, elevando la capacidad expoliadora y represiva de los Estados. 
del Estado. La globalización nos demuestra la viabilidad de un orden policéntrico $\mathrm{y}$, por tanto, nos enseña a desprendernos del Estado $^{59}$.

59 Como ha expresado Antonio Mascaró en su «Teoría del desprendimiento»: «No es un desprendimiento tajante. Es gradual a medida que cada uno va descubriendo nuevas salidas hacia la libertad y la responsabilidad individual. Se agrava el problema de la economía sumergida, dirán los que se han especializado en partir y repartir desde arriba. No, lo que pasa es que la confianza en el Estado del Bienestar se hunde porque éste hace aguas y la gente se espabila y aprende a nadar». Antonio Mascaró, "La Teoría del desprendimiento», Instituto Juan de Mariana, Comentario diario, 9-12-2005 (http:/ / www.juandemariana. org/comentario/395/). 